Poster sessions

\begin{tabular}{llllllll}
\multicolumn{7}{l}{ Abstract P62 Table 1} \\
\hline \multicolumn{7}{l}{ Log FEF } \\
& FEV1 & $\begin{array}{l}25-75 \\
(\%)\end{array}$ & $\begin{array}{l}\text { TLCO } \\
(\%)\end{array}$ & $\begin{array}{l}\text { RV } \\
(\%)\end{array}$ & $\begin{array}{l}\text { mMRC } \\
\text { Score }\end{array}$ & 6MWD & $\begin{array}{l}\text { BODE } \\
\text { index }\end{array}$ \\
\hline $\begin{array}{llllllll} \\
\text { Emphysema }\end{array}$ & & & & & & \\
Score & -0.32 & $-0.42^{*}$ & $-0.69^{*}$ & 0.31 & 0.04 & -0.27 & $0.37^{*}$ \\
Gas & & & & & & & \\
trapping & & & & & & & \\
Score & $-0.50^{*}$ & $-0.50^{*}$ & $-0.68^{*}$ & $0.40^{*}$ & 0.02 & -0.29 & $0.47^{*}$ \\
\%LAA & $-0.47^{*}$ & $-0.42^{*}$ & $-0.51^{*}$ & $0.49^{*}$ & 0.09 & -0.32 & $0.48^{*}$ \\
AWT-Pi10 & -0.02 & 0.03 & 0.29 & -0.02 & -0.06 & 0.07 & -0.08 \\
RVC $856-950$ & $-0.61^{*}$ & $-0.65^{*}$ & $-0.55^{*}$ & $0.51^{*}$ & 0.15 & -0.21 & $0.48^{*}$ \\
\hline
\end{tabular}

Pearson's correlation coefficient of CT markers with lung function and functional parameters.

*indicates statistical significance with $p$ value $<0.05$

analysis of CT scans allows quantification of emphysema, bronchial wall thickening and gas trapping and offers the opportunity to study the heterogeneity of COPD.

This study aims to use quantitative digital software to analyse CT scans from a cohort of COPD patients to define clinically important phenotypes.

Methods Acute Exacerbation and Respiratory Infections in COPD (AERIS) is a longitudinal epidemiological study where patients with moderate to very severe COPD were followed monthly for 2 years. At enrolment subjects had pulmonary function testing and high resolution spiral CT was performed in inspiration and expiration. A sub-cohort of 36 patients is included in this analysis.

CT scans were reported by a thoracic radiologist using a validated scoring system for emphysema and gas trapping. Image analysis was performed using Apollo software. Emphysema was defined as the percent of lungs with low attenuation values below -950 Hounsfield Units (\%LAA) on inspiratory scan. Airway wall thickness was standardised by using the square root of the wall area for a theoretical airway with an internal perimeter of $10 \mathrm{~mm}$ (AWT-Pi10). Gas trapping was calculated using the relative volume change of low attenuation areas from -856 to 950 between the inspiratory and expiratory scans $\left(\mathrm{RVC}_{856-950}\right)$. Results Correlation between the reported CT scores (emphysema and gas trapping) and corresponding quantitative measures (\% LAA and $\mathrm{RVC}_{856-950}$ ) were strong: $\mathrm{r}=0.79$ and $\mathrm{r}=0.5$, respectively $(p<0.05)$. CT scores and quantitative measures for emphysema and gas trapping were significantly correlated with pulmonary function and BODE index (Table 1).

Conclusion In this study we have shown that quantitative chest CT measures correlate with a number of traditional physiological and prognostic markers in COPD. These measures have the potential to be clinically useful imaging biomarkers for the disease and further work will help validate this by investigating the longitudinal changes of the AERIS cohort.

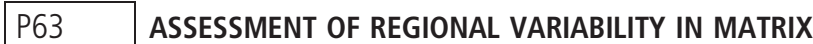 METALLOPROTEINASE CONCENTRATIONS BY CT INFORMED BRONCHOALVEOLAR LAVAGE IN PATIENTS WITH COPD}

${ }^{1} \mathrm{~K}$ Ostridge, ${ }^{2} \mathrm{~S}$ Harden, ${ }^{3} \mathrm{P}$ Elkington, ${ }^{3} \mathrm{KJ}$ Staples, ${ }^{3} \mathrm{~T}$ Wilkinson. ${ }^{1}$ Southampton NIHR Respiratory Biomedical Research Unit, UniversityHospital Southampton Foundation NHS Trust, Southampton, UK; ${ }^{2}$ Department of Radiology, University Hospitals Southampton NHS Foundation Trust, Southampton, UK; ${ }^{3}$ Faculty of Medicine, University of Southampton, Southampton, UK

10.1136/thoraxjn-2014-206260.204
Abstract P63 Table 1 Table showing median values of MMPs corrected for protein concentration and interquartile range in brackets. $\mathrm{P}$ value for paired samples using one-tailed Wilcoxon signed rank Test

\begin{tabular}{llll}
\hline & $\begin{array}{l}\text { Median concentration } \\
\text { in Diseased Lobe } \\
(\mathrm{pg} / \mathrm{ml} / \mu \mathrm{g} \text { protein) }\end{array}$ & $\begin{array}{l}\text { Median concentration } \\
\text { in Preserved Lobe } \\
(\mathrm{pg} / \mathrm{ml} / \mu \mathrm{g} \text { protein) }\end{array}$ & P value \\
\hline MMP-1 & $0.11(0.14)$ & $0.03(0.06)$ & 0.09 \\
MMP-2 & $66.39(66.41)$ & $35.77(27.34)$ & 0.03 \\
MMP-3 & $0.35(0.63)$ & $0.19(0.22)$ & 0.01 \\
MMP-7 & $13.96(41.40)$ & $5.44(12.95)$ & 0.08 \\
MMP-8 & $10.66(17.93)$ & $5.08(22.10)$ & 0.22 \\
MMP-9 & $19.62(14.31)$ & $8.10(17.69)$ & 0.37 \\
\hline
\end{tabular}

Background Matrix metalloproteinases (MMPs) are a family of proteolytic enzymes involved in the normal physiological turnover of the pulmonary extracellular matrix. They have been implicated in animal models of emphysema. However, there have been conflicting results in human studies, largely due to the anatomical regional variability and heterogeneity of COPD not being taken into account. This study aims to understand the role of MMPs in COPD by using CT analysis to guide regional bronchoalveolar lavage (BAL) and employing multiplex profiling of this fluid.

Methods Twelve mild-to-moderate COPD patients (FEV1/FVC ratio $<0.7$, FEV1 $>50 \%$ ) underwent high resolution spiral chest CT. This was reported by a thoracic radiologist and lobes with most and least evidence of disease (emphysema or bronchial wall thickening) were identified. During bronchoscopy $100 \mathrm{ml}$ of saline was instilled into each of these lobes and the BAL was collected. This fluid was filtered and then concentrated 2 -fold by lyophilisation. MMP-1, -2, -3, -7, -8 and -9 were measured using a multiplex ELISA. Sample protein concentration was determined using a Bradford assay. MMP concentration was corrected for BAL protein concentration.

Results MMPs and protein were successfully detected in BAL. Median values for MMP-1, -2, -3, -7, -8 and -9 were all increased in the diseased lobe compared to the relatively preserved lobe. This was significant for MMP-2 and -3 and trended towards significance for MMP-1 and -7 (Table 1).

Conclusion These results suggest that certain MMPs are present in greater quantities in areas of the lungs most affected by COPD, adding to the evidence that they may be involved in the pathogenesis of the disease. This study also demonstrates the regional anatomical variability of COPD in respect to imaging abnormalities and the underlying disease processes. Regional sampling needs to be considered in future studies to enable full understanding of the heterogeneous pathological mechanisms involved in COPD.

\section{P64 EVALUATION OF SALIVA BIOMARKERS AS INDICATORS OF HEALTH STATUS AND EXACERBATIONS IN COPD}

${ }^{1} \mathrm{~N}$ Patel, ${ }^{1} \mathrm{P}$ Jones, ${ }^{1} \mathrm{~V}$ Adamson, ${ }^{1} \mathrm{G}$ Thorpe, ${ }^{2} \mathrm{~J}$ Belcher, ${ }^{1} \mathrm{M}$ Spiteri. ${ }^{1}$ Heart and Lung Directorate, UniversityHospital of North Staffordshire, Stoke on Trent, UK; ${ }^{2}$ School of Computing and Mathematics, KeeleUniversity, Keele, UK

\subsection{6/thoraxjnl-2014-206260.205}

Saliva is increasingly promoted as a suitable alternative diagnostic bio-sample to blood, yet its role in respiratory disease is still to be elucidated. 
Salivary levels of C-Reactive Protein (CRP), Procalcitonin (PCT) and Neutrophil Elastase (NE) were assessed in patients with COPD to determine if saliva could provide an alternative diagnostic bio-sample to blood. As the clinical usefulness of biomarkers relies on correlation to patient events, we also explored the relationship between target saliva analyte levels and wellbeing scores on breathing and activities of daily living (ADL), recorded in a purposeful diary.

The study included 139 subjects: 17 healthy non-smokers; 24 healthy smokers; 98 patients with COPD [Global Initiative for Chronic Obstructive Lung Disease (GOLD) Stage I, 16; Stage II, 32; Stage III, 39; Stage IV, 11]. Participants were assessed over 3 visits, one week apart and involving patient completion of a self-assessment diary, spirometry and, saliva sampling. 22 randomly selected COPD subjects provided simultaneous blood samples. Each salivary biomarker could distinguish across the 3 health status groups; however when adjusted for confounding factors this significance only remained for salivary NE, which was increased in healthy smokers compared to healthy nonsmokers $(\mathrm{p}<0.001)$ and stable COPD subjects $(\mathrm{p}<0.001)$. Patients with an acute exacerbation of COPD $(n=36)$ had a median increase in all 3 salivary biomarkers $(\mathrm{p}<0.001)$. CRP: median $5.74 \mathrm{ng} / \mathrm{ml}$, [interquartile range 2.86-12.25], (95\% Confidence Interval (CI): 3.72-11.47); PCT $0.38 \mathrm{ng} / \mathrm{ml}$, [0.220.94], (95\% CI: 0.31-0.54) and NE $539 \mathrm{ng} / \mathrm{ml}$ [112.25-1264], (95\% CI: 169-982). Salivary CRP and PCT concentrations strongly correlated with their serum counterparts; salivary NE did not. Salivary CRP and PCT levels correlated with breathing scores $(\mathrm{r}=0.14, \mathrm{p}<0.02 ; \mathrm{r}=0.13, \mathrm{p}<0.03$ respectively) but not with activities of daily living. Salivary NE showed no relationship to wellbeing scores.

Salivary CRP, PCT and NE provide clinically relevant information on disease status in COPD, and additionally NE on smoking status in healthy individuals. These results provide the conceptual basis for saliva to be used as a bio-sample in COPD monitoring.

\begin{tabular}{|c|c|c|c|}
\hline \multicolumn{4}{|c|}{ Matched COPD Subjects $(n=36)$} \\
\hline Demographic & Stable & Exacerbation & $P$ value \\
\hline $\mathrm{FEV}_{1}$, $\%$ predicted & $53 \pm 23$ & $48 \pm 19$ & $<0.001$ \\
\hline MRC Score & $5.00,1.25$ & $5.00,1.25$ & $<0.16$ \\
\hline Breathing Score & $3.00,0.00$ & $4.00,1.00$ & $<0.006$ \\
\hline ADL Score & $3.00,1.00$ & $4.00,2.00$ & $<0.014$ \\
\hline \multicolumn{4}{|l|}{ Sputum } \\
\hline Amount & $2.00,2.00$ & $3.00,2.25$ & $<0.001$ \\
\hline Texture & $1.94,0.33$ & $2.06,0.41$ & $<0.05$ \\
\hline Colour & $3.00,1.00$ & $4.00,1.50$ & $<0.001$ \\
\hline \multicolumn{4}{|l|}{ Salivary Biomarkers ${ }^{b}$} \\
\hline CRP, ng/ml & $1.61,1.10$ & $7.35,10.04$ & $<0.001$ \\
\hline $\mathrm{PCT}, \mathrm{ng} / \mathrm{ml}$ & $0.09,0.06$ & $0.50,0.71$ & $<0.001$ \\
\hline $\mathrm{NE}, \mathrm{ng} / \mathrm{ml}$ & 128,190 & 769,1680 & $<0.001$ \\
\hline \multicolumn{4}{|c|}{$\begin{array}{l}\text { a, Mean } \pm \text { standard deviation } \\
\text { b, Median, inter-quartile range } \\
\text { COPD = Chronic Obstructive Pulmonary Disease; FEV }{ }_{1}=\text { Forced Expiratory Volume in } 1 \text { sec- } \\
\text { ond; } M R C=\text { Medical Research Council; ADL = Activity of Daily Living; CRP = C-Reactive } \\
\text { Protein; PCT = Procalcitonin; NE = Neutrophil Elastase. } \\
\text { P values represent the difference between stable and exacerbation phase. }\end{array}$} \\
\hline
\end{tabular}

\section{P65 \\ STATIC BALANCE DEFICIT IN CHRONIC OBSTRUCTIVE PULMONARY DISEASE: PREVALENCE, CLINICAL CHARACTERISTICS AND RISK OF SIGNIFICANT FALLS}

JL Canavan, SSC Kon, CM Nolan, SE Jones, MI Polkey, Wd-C Man. NIHR Respiratory Biomedical Research Unit, Royal Brompton and Harefield NHS Foundation Trust and Imperial College, UK, Harefield, Middlesex, UK

\subsection{6/thoraxjnl-2014-206260.206}

Background Balance deficits are associated with increased risk of falls. The tandem stand (maintaining heel to toe stance for 10 seconds or more) is an established practical measure of static balance, and is associated with increased risk of falls and disability in community dwelling adults. The aim of the study was to establish the prevalence of static balance deficit in outpatients with stable COPD and any association with exercise capacity, lower limb muscle function and health related quality of life. Furthermore, it is not known whether the tandem stand predicts future risk of significant falls in patients with COPD.

Method 174 outpatients with stable COPD (mean (SD) age 70 (9) years, $\mathrm{FEV}_{1} 50(21) \%$ predicted) were stratified according to their ability to successfully complete the tandem stand. The incremental shuttle walk (ISW) test, habitual gait speed over 4 metres (4MGS), quadriceps maximal voluntary contraction (QMVC), the COPD assessment test (CAT), physical activity levels (defined as time spent in $>3$ METS according to the modified Minnesota Leisure-time Physical Activity Questionnaire) were also recorded. Self-reported falls and significant falls (defined as fall resulting in fracture or cerebral injury), corroborated by primary care records, were recorded over the following 12 months. Results 24\% could not complete the tandem stand. Compared to those able to complete a tandem stand, these patients were significantly older, had lower maximal exercise capacity, weaker quadriceps muscle force and reduced daily physical activity (Table 1). No significant falls were reported within the whole cohort, but 20 patients (11\%) reported non-injury falls after 12 months of follow-up (failed tandem: 19\% versus successful tandem: $9 \% ; \mathrm{p}=0.10$ )

Conclusion Static balance deficit is common in patients with COPD, and is associated with reduced exercise capacity, quadriceps weakness and reduced daily physical activity. The tandem stand does not predict future risk of falls. Significant falls were not observed in this cohort.

\begin{tabular}{|c|c|c|c|c|}
\hline & $\begin{array}{l}\text { Impaired } \\
\text { balance } \\
(n=42)\end{array}$ & $\begin{array}{l}\text { Completed } \\
\text { Tandem stand } \\
(\mathrm{n}=132)\end{array}$ & $\begin{array}{l}\text { Mean } \\
\text { difference } \\
(95 \% \mathrm{Cl})\end{array}$ & p-value \\
\hline Age (years) & $74(9)$ & $69(9)$ & 5.1 (2 to 8$)$ & 0.002 \\
\hline $\mathrm{FEV}_{1}$ (\% predicted) & $55(39,77)$ & $48(30,61)$ & $9(4)$ & 0.02 \\
\hline ISW (metres) & $166(109)$ & $252(127)$ & $-90(-130$ to -40$)$ & 0.0001 \\
\hline САТ & $20.3(7.7)$ & $20.4(7.4)$ & $-0.1(-2.7$ to 2.5$)$ & 0.95 \\
\hline Peak QMVC (kg) & $21.8(8.9)$ & $25.3(9.0)$ & $-4.7(-8.5$ to -0.9$)$ & 0.02 \\
\hline 4MGS (m/s) & $0.81(0.2)$ & $0.98(0.2)$ & 0.17 (0.1 to 0.04$)$ & $<0.0001$ \\
\hline \multicolumn{5}{|l|}{ Activity in $>3$ METS } \\
\hline (minutes) & $110(40,344)$ & $285(104,567)$ & $14(-272$ to 301$)$ & 0.92 \\
\hline \multicolumn{5}{|l|}{ Number reporting } \\
\hline falls in 12 months & 8 & 12 & - & 0.10 \\
\hline
\end{tabular}

